\title{
Simulation numerical analysis on stability of foundation pit under the conditions of heavy rainfall
}

\author{
Fengzhan Cui ${ }^{1, a}$, Tao Wang ${ }^{1, b}$ \\ ${ }^{1}$ School of mechanics \& civil engineering, China University of Mining and Technology (Beijing), Beijing, \\ 100083, China \\ acuifengzhan2014@163.com, bwangtao123@qq.com
}

Keywords: FLAC3D numerical simulation; foundation stability; intensive rainfall; lateral displacement Abstract. In view of the influence of complex condition on the basic of the accident and caused huge losses, this paper uses the FLAC3D numerical simulation analysis on the foundation stability under intensive rainfall simulation software, to provide a basis for site selection of reasonable support method. Research shows that: in the foundation pit of $-3 \mathrm{~m},-5.8 \mathrm{~m},-11 \mathrm{~m}$ position with bolting after foundation pit slope stress, displacement evolution rules, to determine the depth of pit in the -9 mposition, -5.8 manchor reinforcement of foundation pit slope state, the lateral displacement is smallest, foundation pit reinforcement effect is the best, in this state, the slope lateral displacement amounts were reduced to design supporting condition of the $44.8 \%, 40.55 \%$, $38.74 \%, 39.61 \%$, can meet the requirements of safety and stability

\section{Introduction}

Foundation pit engineering accidents not only cause different degrees of loss to the national economy and people's life and property safety, causing casualties, delay, cost of additional negative effect and affect the surrounding residents normal life, increase the investment account, but also adversely affect the city construction and enterprise image[1]. Many factors influence the pit accident, in which the uncertainty is a major cause of foundation pit accident prone. In this paper, telescience detection laboratory foundation pit engineering rainstorm disaster slope deformation based on the numerical simulation method, the simulation analysis of surrounding rock stability to keep the concrete reinforcement measures, and provide the basis for the site[2].

\section{To determine the simulation programs}

The simulation analysis after excavation slope movement, stress evolution, as a comparison of different supports the supporting effect of the foundation;

The simulation analysis under the action of the rainstorm design support scheme (pile cap beam section size is $900 \mathrm{~mm} * 500 \mathrm{~mm}$; slope protection pile diameter $800 \mathrm{~mm} \mathrm{~L}=1.6 \mathrm{~m}$, pile spacing, pile length $21.0 \mathrm{~m}$ (embedded depth 5.75m); the first anchor elevation $-4.67 \mathrm{~m}$, angle of 15 degrees to 20 degrees, the second anchor elevation $-8.87 \mathrm{~m}$, tilt angle of 15 degrees, third anchor elevation $-12.87 \mathrm{~m}$, the angle of 15 degrees, second, three increase in jet expansion head anchor, enlarged head bolt diameter $400 \mathrm{~mm}$ ) shoring of foundation pit slope displacement and stress of the evolution;

Simulation analysis after storm effect in foundation design of supporting scheme for another in the north and south slope of the $-3 \mathrm{~m},-5.8 \mathrm{~m},-11 \mathrm{~m}$ and the three row of position play anchor strengthening supporting foundation pit slope displacement and stress evolution rules, to provide a basis for reinforcement of foundation pit.

\section{Establishment of the numerical model}

According to the simulation scheme, combined with the specific shape and size of the foundation pit, establish the model is shown in Fig. 1. For the boundary effect and the surrounding effectively simulate the additional stress, pit at the center, model $80 \mathrm{~m}$ long from north to south, east-west width of $120 \mathrm{~m}$, high $30 \mathrm{~m}, 15-30 \mathrm{~m}$ 
height range for the foundation soil, in the range of $0-15 \mathrm{~m}$ base soil. Soil by Mohr-Coulomb yield condition for the failure criterion of elastic plastic constitutive model, slope protection pile using pile element simulating using cable element simulating anchor.

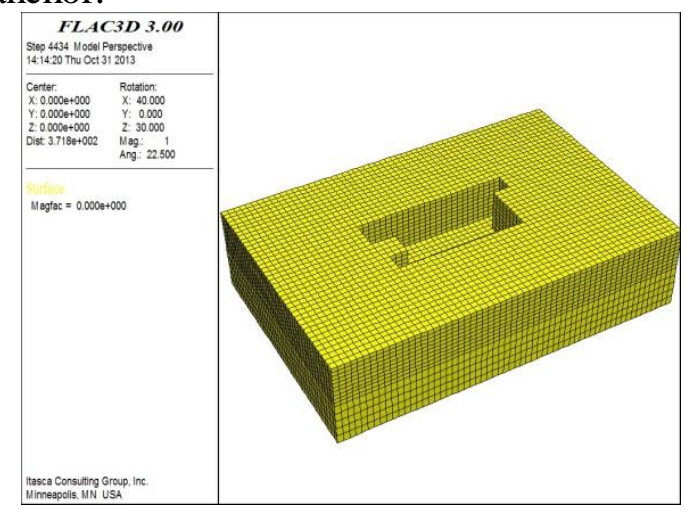

Fig.1 Pit model graph

\section{No supporting analysis and design support state displacement of deep foundation pit slope evolution}

For comparison, the effective pile anchor supporting an important role in maintaining the stability of foundation pit, the influence of rainstorm, simulation analysis of foundation pit without supporting state and supporting state of slope deformation, to obtain the slope stress, displacement evolution.

Torrential rain erosion, no support and design support state north and South Slope along the depth direction displacement evolution curve is shown in Fig. 2. Can be seen, both sides slope lateral displacement consistent, along the direction of slope displacement of deep foundation pit, increased first and then decreased, in the 4-5m range of depth, position of slope movement reaches a maximum value, which, in the northern slope, no support under the condition of the maximum lateral displacement reached $73.57 \mathrm{~mm}$, and in supporting the state in its side shift weight is $58.09 \mathrm{~mm}$, the reinforcement effect of support structure, the side move to reduce the amount of $21.04 \%$; in the southern position, the lateral displacement amount is smaller in the north slope, no support under the condition of the maximum lateral displacement quantity reaches $64.74 \mathrm{~mm}$, while in the support state its lateral displacement amount is $55.66 \mathrm{~mm}$, in the reinforcement effect of support structure, the side shift reduce $14.03 \%$.

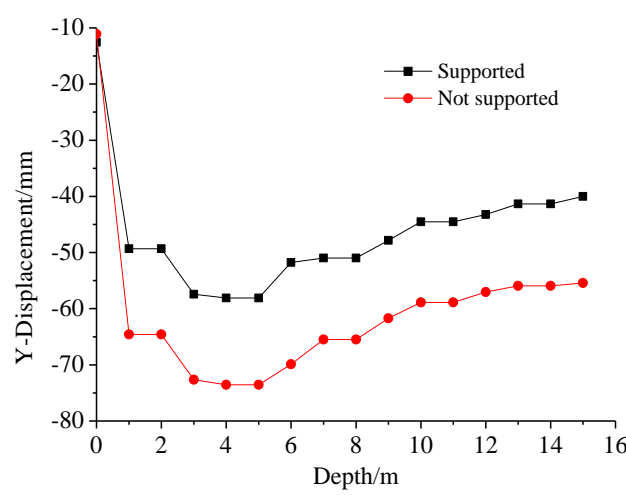

(a)

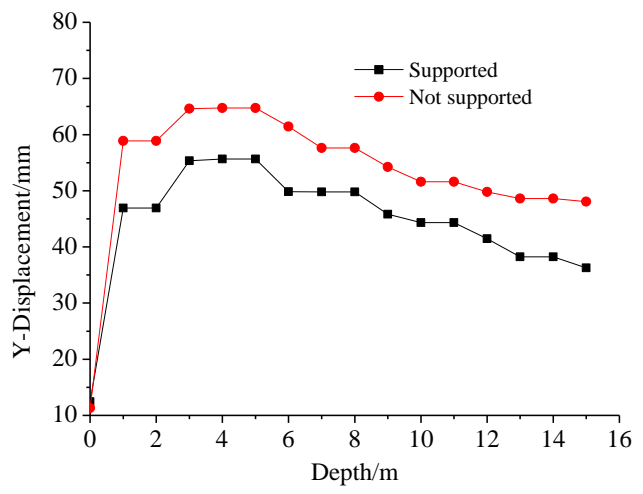

(b)

Fig.2 Support and design support state north and South Slope along the depth direction displacement evolution curve

No support and design of foundation pit support state, $-9 \mathrm{~m}$ deep position of slope displacement evolution curve are shown in Fig. 3, 4. In the two state, with increasing distance and pit volume showed a gradual decreasing trend, the slope side shift. In the absence of supporting condition, foundation pit, west slope, south slope, east slope on the northern slope of the displacement were respectively $45.64 \mathrm{~mm}, 359.9 \mathrm{~mm}, 69.89 \mathrm{~mm}$, $61.45 \mathrm{~mm}$, wherein, the western slope of the positive angle position displacement maximum, as the main weak surface excavation damage; in the design of foundation pit support state, Dongpo, west slope, south slope, 
north slope displacement were respectively $40.98 \mathrm{~mm}, 42.94 \mathrm{~mm}, 51.76 \mathrm{~mm}, 49.84 \mathrm{~mm}$, in a pile, anchor strengthening support, Xi Po Yang angle position control effectively, reduce for foundation pit failure secondary weak plane, and the north and the south slope is due to the large span, become the foundation pit failure mainly weak plane.

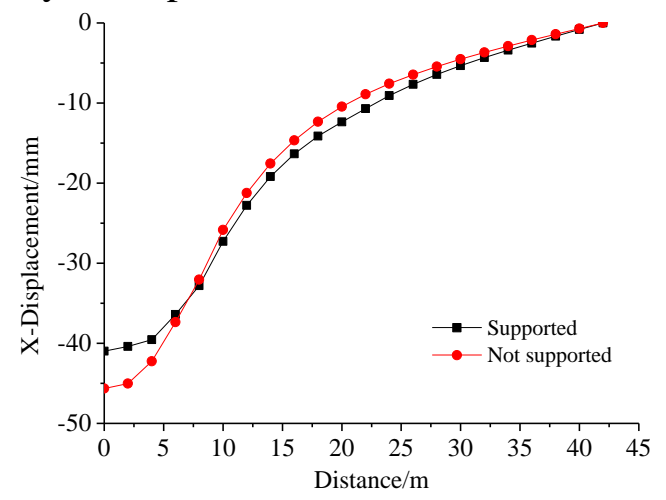

(a)

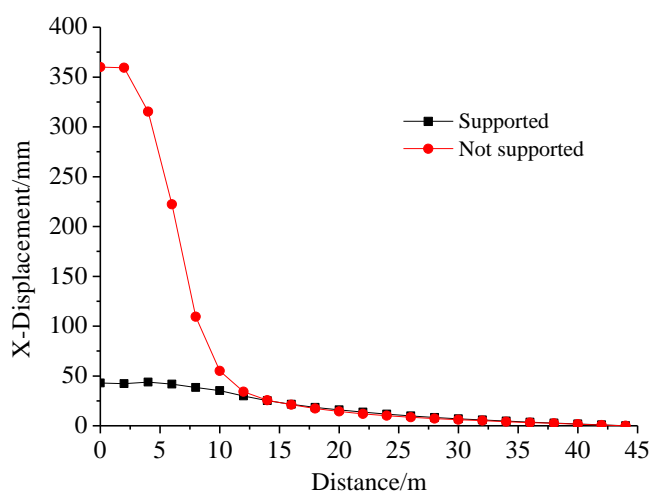

(b)

Fig.3 -9m depth of foundation pit slope with things and evolution curve distance increased displacement of deep foundation pit

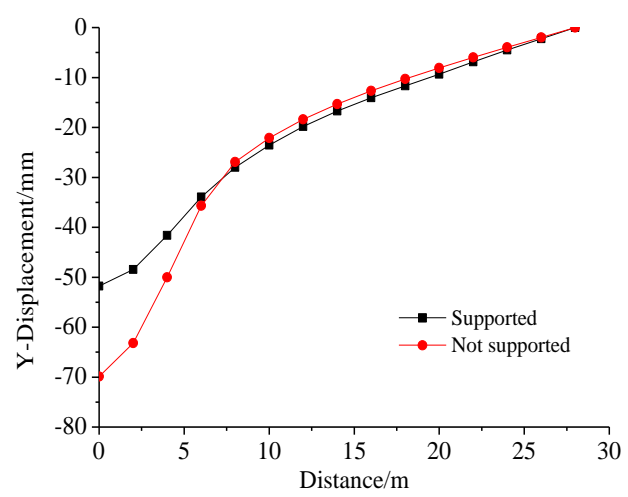

(a)

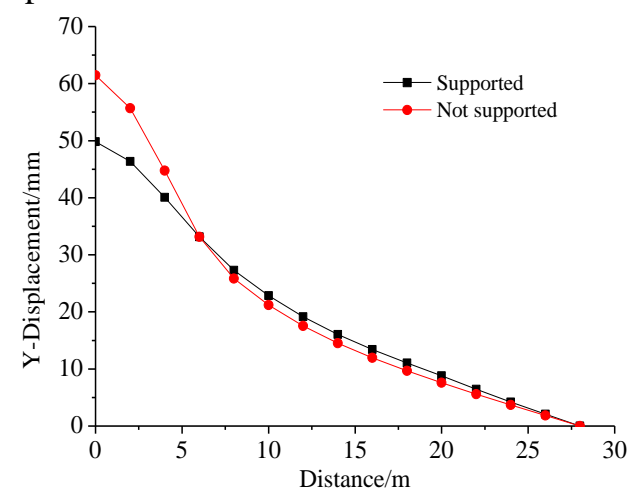

(b)

Fig. 4 -9m depth of foundation pit with North and south slope evolution curve of displacement of foundation pit with increasing distance

\section{Analysis on the evolution of displacement of deep foundation pit slope of different strengthening support state law}

Heavy attack after foundation pit slope move, in order to effectively control the deformation of foundation pit, maintain normal operation of the foundation pit, decided to use the anchor reinforcement, in order to obtain the effective reinforcement of foundation pit excavation, location, select $-3 m-5.8 m,-11 \mathrm{~m}$ position respectively with the anchor bolt is simulated and analyzed, the evolution law of foundation pit slope displacement are obtained, providing basis for selection of anchor position for foundation pit reinforcement, concrete analysis is as follows.

In the design of deep foundation pit supporting state, $-3 \mathrm{~m},-5.8 \mathrm{~m},-11 \mathrm{~m}$ position with bolting after North and South Slope along the depth direction displacement evolution curve are shown in Fig. 5. As can be seen, along the direction of the displacement of slope of deep foundation pit, first increased and then decreased. On both sides of the slope lateral displacement law of basically the same, in the 4-5m range of depth, slope movement reaches a maximum value, which, in the northern slope of the position, the design of support under the condition of the maximum lateral displacement reached $58.09 \mathrm{~mm}$, and the increase of anchor reinforcement in the $-3 \mathrm{~m}$ position, the side shift is reduced to $41.71 \mathrm{~mm}$, at the $-5.8 \mathrm{~m}$ position to increase the bolts the lateral displacement, reducing the amount of $20.8 \mathrm{~mm}$, increasing the anchor reinforcement in the $-11 \mathrm{~m}$ position, the lateral displacement is reduced to $47.68 \mathrm{~mm}$, increase the bolts in the slope displacement decrease the maximum in the $-5.8 \mathrm{~m}$ position, reduced to $35.8 \%$ design supporting state, $-3 \mathrm{~m}$ position 
increase bolts in its side move to reduce the amount of toilet paper, bolt after strengthening the side shift reduce minimum increase in $-11 \mathrm{~m}$ position. The southern slope of the corresponding supporting state by its side shift is consistent, the value of $41.15 \mathrm{~mm}, 20.55 \mathrm{~mm}, 46.3 \mathrm{~mm}$, it can be seen, increase the bolt to control slope movement effect was obvious in the $-5.8 \mathrm{~m}$ position, can maintain the stability of foundation pit slope.

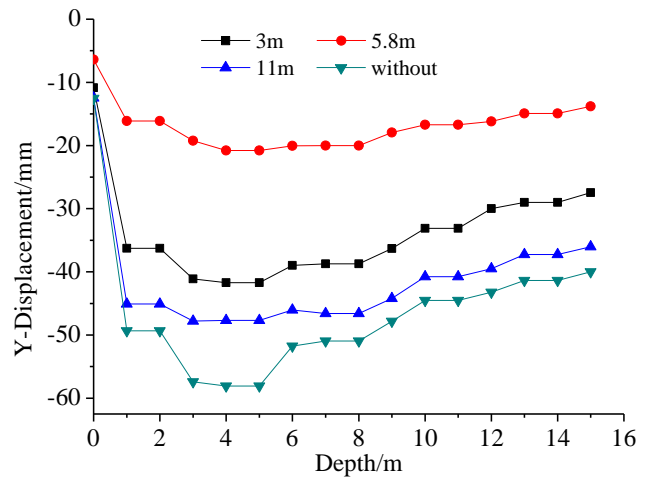

(a)

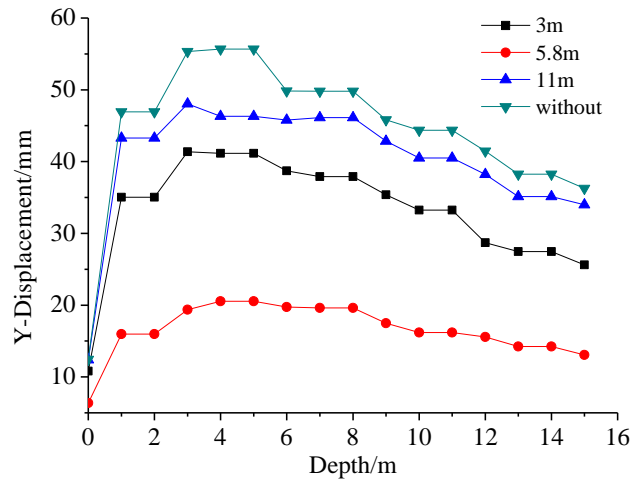

(b)

Fig. 5 To strengthen the support state north and South Slope along the depth direction displacement evolution curve

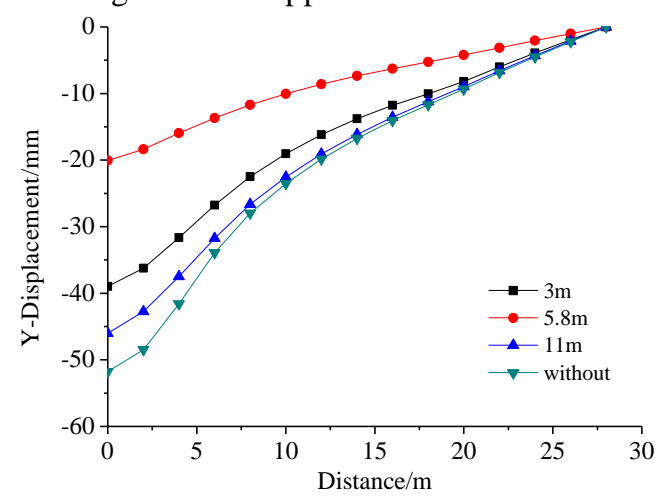

(a)

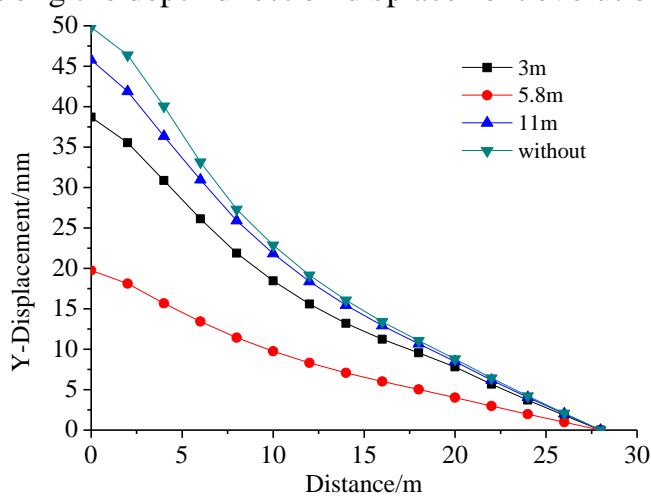

(b)

Fig. 6 -9m depth of foundation pit with North and south slope evolution curve of displacement of foundation pit with increasing distance

In the design of deep foundation pit supporting state, $-3 \mathrm{~m},-5.8 \mathrm{~m},-11 \mathrm{~m}$ position with anchor bolt, foundation pit deep $-9 \mathrm{~m}$ position of slope displacement evolution curve is shown in Fig. 6. In addition to foundation pit west slope position affected the positive angle, slope lateral displacement fluctuations, with increasing distance and foundation pit, and the rest slope lateral displacement volume showed a gradual decreasing trend. Foundation pit deep $-9 \mathrm{~m}$ position of different reinforcement slope displacement state statistics. In the state of $-3 \mathrm{~m}$ anchor foundation pit reinforcement, Dongpo, west slope, south slope, north slope displacement were respectively $34.06 \mathrm{~mm}, 31.66 \mathrm{~mm}, 38.97 \mathrm{~mm}, 38.72 \mathrm{~mm}$; in the state of $-5 \mathrm{~m}$ anchor foundation pit reinforcement, Dongpo, west slope, south slope, north slope displacement were respectively $18.36 \mathrm{~mm}, 17.25 \mathrm{~mm}, 20.05 \mathrm{~mm}, 19.74 \mathrm{~mm}$ in the state of $-11 \mathrm{~m}$ anchor; reinforcement, foundation pit Dongpo, west slope, south slope, north slope displacement were respectively $40.44 \mathrm{~mm}, 40.3 \mathrm{~mm}, 46.02 \mathrm{~mm}, 45.8 \mathrm{~mm}$. As can be seen, in the state of the strengthened $-5.8 \mathrm{~m}$ bolt, foundation pit slope side of the minimum displacement, foundation pit reinforcement effect is the best, in this state, the slope lateral displacement amounts were reduced to the design of support under the condition of $44.8 \%, 40.55 \%, 38.74 \%, 39.61 \%$.

\section{Further reinforce the evolution of displacement of foundation pit slope under state law analysis}

Add anchor deep foundation pit slope reinforcement effect as compared to $-5.8 \mathrm{~m}$, seeking the best basis pit reinforcement, to control the deformation of foundation pit excavation, select $-3 \mathrm{~m}$ and $-5.8 \mathrm{~m},-3 \mathrm{~m}$ and $-11 \mathrm{~m}$, $-5.8 m$ and $-11 m,-3 m+-5.8 m$ and $-11 m$ position with anchor bolt is simulated and analyzed, obtain the foundation pit slope stress, displacement evolution law, provide the basis for determining mode for reinforcement of foundation pit. 
Foundation pit deep position of $-5.8 m,-3 m+-5.8 m,-3 m+-11 m,-5.8 m+-11 m,-3 m+-5.8 m+-11 m$ position with bolting after foundation pit slope of North and south along the depth direction displacement evolution curve is shown in Fig. 7. Can be seen along the direction of displacement of slope of deep foundation pit, first increased and then decreased. On both sides of the slope lateral displacement rules are basically the same, in the 4-5m range of depth, slope movement reaches a maximum value, which, in the northern slope of the position, state the maximum lateral displacement reached $20.8 \mathrm{~mm}$ strengthened $-5.8 \mathrm{~m}$ bolt, $-3 \mathrm{~m}+-5.8 \mathrm{~m}$ bolt reinforcement in, the side shift is reduced to $19.57 \mathrm{~mm}$, the $-3 \mathrm{~m}+11 \mathrm{~m}$ anchor rod reinforcement, the lateral displacement to reduce the amount of $21.73 \mathrm{~mm}$, the $-5.8+-11 \mathrm{~m}$ anchor reinforcement, the lateral displacement is reduced to $18.98 \mathrm{~mm}$, in the $-3 \mathrm{~m}+-5.8 \mathrm{~m}+-11 \mathrm{~m}$ bolts in the slope displacement decrease the maximum, reduced to $18.15 \mathrm{~mm}$, but overall the slope lateral displacement quantity difference. The southern slope of the corresponding supporting state by its side shift slightly smaller than the north slope, the value of $19.32 \mathrm{~mm}, 21.42 \mathrm{~mm}, 18.69 \mathrm{~mm}, 17.88 \mathrm{~mm}$. As can be seen, to continue to strengthen support to reduce the side shift effect is smaller in the foundation reinforcement $-5.8 \mathrm{~m}$ position bolt, consider increasing the degree of difficulty and the cost of construction, increase the bolting is economical and reasonable in the $-5.8 \mathrm{~m}$ position.

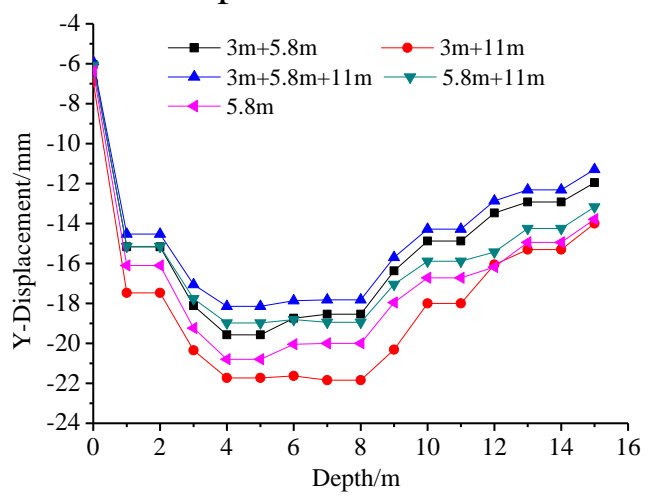

(a)

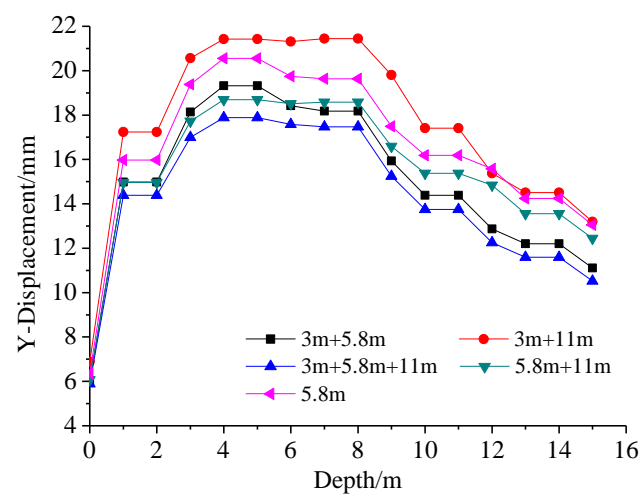

(b)

Fig. 7 To further strengthen the support state north and South Slope along the depth direction displacement evolution curve

\section{Conclusion}

In this paper, using the FLAC3D numerical simulation analysis on the foundation stability under intensive rainfall simulation software, the main conclusions are as follows.

Obtained by simulation and analysis in the absence of support and design of foundation pit slope supporting state of stress, displacement evolution rules, clear the pile body, support structure anchor in a major role in maintaining the stability of the foundation pit slope in.

Obtained by simulation and Analysis on foundation pit $-3 \mathrm{~m},-5.8 \mathrm{~m},-11 \mathrm{~m}$ position with bolting after foundation pit slope stress, displacement evolution rules, to determine the depth of pit in the $-9 \mathrm{~m}$ position, $-5.8 \mathrm{~m}$ anchor reinforcement of foundation pit slope state, the lateral displacement is smallest, foundation pit reinforcement effect is the best, in this state, the slope side shift reduced respectively for the design of support under the condition of $44.8 \%, 40.55 \%, 38.74 \%, 39.61 \%$, can meet the requirements of safety and stability.

\section{References}

[1] Hongsong Wei. Alley of Engineering [M]. Beijing: Coal industry publishes, 2007.

[2] Dongming Guo, Renshu Yang, Kunlun Hu etc. Experimental Research on Long Hole Loose Blasting Mechanized Kaolin Mining [J]. Mining and Safety Engineering Journal, 2009, 26(4):428-432. 